\title{
De una memoria truncada a una historia majestuosa: el caso de Lucas Alamán
}

\author{
ERIC VAN YOUNG
}

En el artículo se ofrecen algunas reflexiones acerca de la escritura de biografías. Se utiliza la vida de Lucas Alamán, el gran estadista conservador e historiador del siglo XIX, como estudio de caso. Se propone la posibilidad de echar mucha luz sobre la vida, las obras históricas y la postura política de Alamán mediante un análisis de su memoria autobiográfica, escrita durante la década de 1830 y nunca publicada. En este documento se revela la preocupación del personaje por la pérdida de estatus social y fortuna de su familia, y su tendencia a entender la historia del México independiente en términos de fracaso.

PALABRAS CLAVE: Lucas Alamán, biografía, autobiografía, memoria, Independencia, estatus social

From a Truncated Memoir to a Magisterial History: The Case of Lucas Alamán

The article offers some reflections on the writing of biography, using as a case study the life of Lucas Alamán, the great nineteenth-century statesman and historian. It proposes that much light can be thrown on his life, historical works, and political position by an analysis of his unpublished autobiographical memoir written during the decade of 1830. This document reveals the preoccupation of its author with his family's loss of social status and wealth, and the tendency of Alamán to understand the history of independent Mexico as one of failure.

KEYWORDS: Lucas Alamán, biography, autobiography, memoir, memory, Independence, social status 
n 1799, durante la expedición francesa que encabezó Napoleón en Egipto, se descubrió la Piedra Rosetta. Por extensión metafórica, este término ha llegado a tener un significado más amplio como clave para descifrar información codificada. En el oficio de la biografía hay mucho qué descifrar. Como historiador, uso la palabra "oficio" en lugar de "arte" porque mi manera de escribir una biografía ha sido moldeada por mi formación y mi trayectoria como historiador. En mi caso, pienso que aplico un conjunto de herramientas que ya poseo para solucionar un tipo de problema diferente, en vez de trabajar en una disciplina del todo distinta. Muchas veces los historiadores trabajan con historias de vida condensadas o fragmentarias, y por esa razón reclaman con energía que tienen credenciales de biógrafos. El hecho de que muchos historiadores descuiden las psicologías de sus sujetos al escribir estas minibiografías, pues se enfocan casi por completo en sus sociologías, no es una descalificación obligada o permanente al título que reclaman, sino sólo un accidente desafortunado que la vieja costumbre disciplinaria ha santificado.

Para seguir con el tema del desciframiento, sugiero que la dinámica interna de una vida pocas veces permite el acceso de un sujeto distinto al que se analiza, que aun así se esconde de sí mismo de manera intencional o no. Esta obstinada opacidad que ofrecen los sujetos biográficos se resiste a nuestro empeño, a pesar de que hay un código de relatos más o menos detallados e íntimos de un "yo", como diarios, cartas informales, memorias, etcétera, que nos guían en el desciframiento. La presentación de este "yo" es siempre una representación, en el sentido de que siempre hay una audiencia para ella. A veces la audiencia está formada sólo por el narrador, el orador o el escritor mismo, pero es una audiencia al final. Donde hay audiencias para la representación del yo, de manera inevitable borramos, fabricamos, mezclamos, condensamos. Dicho de otro modo, mentimos conscientemente o no. La presentación del yo tiene mucho en común con otros procesos narrativos relacionados con la exclusión y la inclusión, es decir, de manera permanente contamos historias más o menos organizadas en las que es probable que dejemos de lado tanto como incluimos. El acto de seguir estas representaciones hasta donde sea posible y remontar la corriente de la narrativa se convierte en una especie de viaje de exploración o tal vez de historia de detectives, salvo que nunca encontraremos las fuentes del Nilo ni el paradero del verdadero Halcón Maltés, el de oro, no el de plomo. 
He pasado años investigando y escribiendo una biografía del estadista, empresario e historiador $\mathrm{Lu}-$ cas Alamán. Como biógrafo que piensa en su vida y su carrera, me ha sorprendido concluir que su trayectoria, el arco de su vida, fue ante todo un arco de fracaso. Cualesquiera que hayan sido las realidades políticas, sociales y económicas de su tiempo, Alamán trazó este fracaso al contar la historia de su país en la mayor de sus obras históricas, los volúmenes de la Historia de Méjico, por la que hoy es reconocido. Me he asignado la tarea de dibujar en este ensayo ese arco biográfico desde las memorias tempranas, incompletas e inéditas, de Alamán, hasta la historia magistral del movimiento mexicano de independencia y sus antecedentes, que publicó en sus últimos cinco años de vida. Sin embargo, si consideramos que estoy pensando en el género de la biografía en términos más amplios, desde las perspectivas teórica y metodológica, esto es en realidad un ensayo sobre el tratamiento de las fuentes y los límites de lo que podemos inferir a partir de ellas, una especie de ejercicio de laboratorio. Creo que la lectura atenta de esas memorias fragmentarias, que Alamán comenzó a escribir a los 40 y tantos, cuando pasaba por un periodo de fuertes presiones políticas, ofrece una clave importante para entender varios aspectos de su vida. Podría decirse que es una Piedra Rosetta mediante la cual es posible determinar una asombrosa coherencia entre el pensamiento y la trayectoria de un hombre público muy correcto que revelaba poco de sí mismo.

Se presentaba Alamán, según toda referencia, como un hombre de la alta burguesía, reservado y más bien impasible, de profundo intelecto y muy cultivado. Guillermo Prieto (1906: 233 y ss.), por ejemplo, describe la casa de Alamán por los años de la guerra del 47 como un modelo de decoro entre la elite, carente de ostentación y llena de virtud, regularidad, decencia, orden y un silencio casi escalofriante. Los viajeros de esa misma época, entre ellos Fanny Calderón de la Barca (1970: 290-292), coinciden al describir a Alamán con un tono de voz bajo, una conducta estudiada y una profunda cultura. Casi todas las descripciones contemporáneas de su persona coinciden con éstas.

Es poco lo que he recuperado de su correspondencia realmente personal, en la que no hay ni una carta escrita para o por su esposa, o sus dos hijos mayores, uno sacerdote y el otro abogado. Es probable que esta escasez de fuentes de naturaleza íntima refleje en parte los accidentes de la supervivencia documental que enfrentan todos los historiadores y biógrafos. Cualesquiera que hayan sido las causas, no obstante la avalancha de papeles públicos que generó y los al menos ocho gruesos tomos de historia que publicó, el hombre que esgrimía la pluma sigue siendo un tanto enigmático. Todo esto crea considerables dificultades para que el biógrafo acceda al fuero interno de Alamán, a los resortes emocionales y experienciales de su comportamiento. Mucho de lo que he podido reconstruir se basa en lo que él sabía - por medio de la correspondencia, la experiencia personal, la conversación, la lectura y otras fuentes de información-, más que en lo que pensaba o sentía. A menudo se encuentra en el centro de su propia vida como una especie de sombra, definido por la luz a sus espaldas o por el espacio negativo en torno suyo. Esta opacidad — si acaso podemos decir que las sombras son opacas- le confiere más importancia a las memorias inconclusas que aquí analizo.

Puesto que la mayoría de los mexicanos, incluidos muchos historiadores, sólo conocen vagamente su vida, más allá de la impresión de que era políticamente conservador o reaccionario - un Joseph de Maistre mexicano, por su pensamiento político y social, y un Metternich, por su conducción de las relaciones internacionales-, quisiera delinear de manera somera algunos puntos destacados. Aunque tuvo muchos amigos y defensores, así como detractores y enemigos durante su turbulenta carrera política, bástenos decir que su reputación en la historia de México tiende hacia el negro. Su 


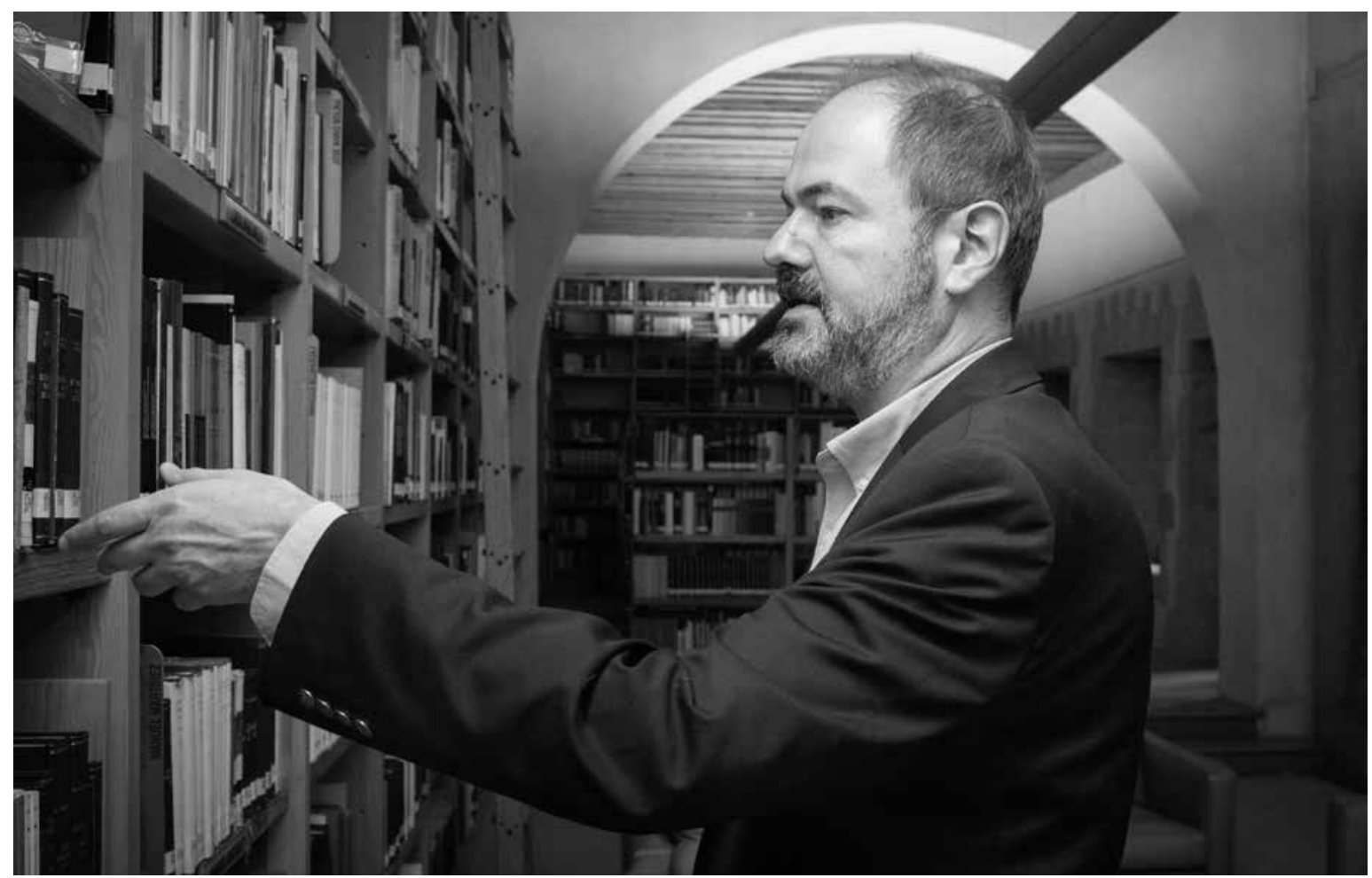

Rodrigo GonZÁleZ • Juan Villoro, periodista, escritor, futbolero y miembro del Colegio Nacional. Ciudad de México, octubre de 2015.

gran contemporáneo y enemigo político, el tribuno liberal José María Luis Mora, alguna vez se refirió a él como "el hombre de mente macabra", de "ideas exageradas [...] que amó el poder desmedidamente no para hacer bien, sino para aprovecharse de sus ventajas". ${ }^{1}$ Un observador estadounidense casi contemporáneo acusó a Alamán de asesinar al menos a dos oponentes políticos por propia mano bajo circunstancias un tanto extrañas. Lo describió como un estadista que desde el poder "no vacilaría en arrastrar por el suelo los derechos de los ciudadanos [de México]" (Robinson, 1848). Éstas y otras opiniones negativas sobre su persona, sostenidas por contemporáneos suyos y por historiadores de épocas posteriores, fueron motivadas por su defensa del régimen monárquico como solución para los males políticos de México, de la década de 1840 en adelante; por su intermitente asociación con Antonio
López de Santa Anna, el presidente perenne, y por su complicidad en el asesinato de Vicente Guerrero. También ha estado en su contra el destacado lugar que ocupaba en la genealogía ideológica del antiliberalismo en México.

Sin embargo, como actor y figura histórica es de gran interés. Muchas veces fue el ministro central del gobierno republicano, como secretario de Relaciones Interiores y Exteriores. La última ocasión fue en 1853, como arquitecto del régimen final de Santa Anna. Alamán, uno de los mayores pensadores de la época en el campo de la economía política, fracasó una y otra vez como empresario privado, y murió en

1

BLAC, Valentín Gómez Farías Papers, item 1182. José María Luis Mora, París, a Valentín Gómez Farías, ciudad de México, 20 de mayo de 1845. 
1853, mucho más pobre de lo que era diez años antes. ${ }^{2}$ De mayor importancia —al menos para el tipo de biografía que escribo- es el papel que tuvo en la modernización de México. Sus modelos, así como los de otros pensadores y estadistas de la época, eran noratlánticos, sin duda, no obstante sus temores en cuanto al expansionismo del poderoso vecino del norte. Desde su primer periodo como ministro, entre 1823 y 1825 , consideraba que el acercamiento diplomático y comercial con la Gran Bretaña era el único contrapeso plausible al floreciente poder económico y las ambiciones territoriales de Estados Unidos. De hecho, el problema de Texas ensombreció toda su carrera como estadista al igual que la pérdida de territorio en la guerra del 47 sus últimos años de vida. Alamán veía a la Gran Bretaña como el modelo de modernización más viable, y por ende, como el camino para salir de la condición colonial y superarla. Admiró las estables instituciones monárquicas, el liberalismo moderado y la creciente fuerza industrial del Reino. No es de extrañar que sintiera fascinación por Edmund Burke, gran pensador y político irlandés, cuya obra maestra, Reflections on the Revolution in France (2001), fue uno de los constructores modernos más importantes del conservadurismo. Alamán leía con avidez las obras de otros pensadores políticos y sociales de la época. Veía en la industrialización el camino hacia el futuro en una sociedad que en sus tiempos era abrumadoramente agraria. En su madurez, luchó para resolver varias preguntas respecto a México, entre ellas, el carácter y los límites del republicanismo; el papel de una aristocracia no oficial, sino con talento natural para guiar el destino del país y contener la fuerza explosiva de la política popular; el problema racial en una sociedad con esencia de una gran tradición cultural indígena, cuya población mayoritaria seguía siendo una subclase étnicamente señalada; los postulados de la ciencia versus la doctrina y la devoción católicas, y el problema clave de cómo recordar los tres siglos de gobierno colonial español.
Antes de regresar a las memorias truncas de mi título, quisiera presentar una nota introductoria acerca del papel de la psicología en mi biografía de Lucas Alamán, una cuestión que todos los biógrafos deben plantearse en algún momento. Hablando con franqueza ante mis colegas biógrafos e historiadores, dudo mucho que intentara hacer una psicobiografía de Alamán —una biografía en la que aplicara consideraciones psicoanalíticas como herramientas de interpretación-, aun cuando tuviera el material para hacerlo, que no tengo. Desde tiempos de Sigmund Freud, el campo de juego se ha ensuciado con tantos esfuerzos fallidos en el género, que las probabilidades de fracaso parecen tristemente altas. El paradigma se ha teñido con cierto descrédito gracias a las argumentaciones psicologistas paradójicamente reduccionistas de algunos practicantes del género. Las califico de paradójicas porque se oponen a la idea psicoanalítica de la sobredeterminación, que en la biografía de cualquier persona incluiría la influencia de "los tiempos" así como los procesos internos de "la vida". En cuanto a mí, carezco de la arrogancia que sospecho esencial para emprender un proyecto así, incluso a veces me he preguntado si debería estar escribiendo una biografía, por principio de cuentas. Si la respuesta es "sí", me pregunto si es moral, a la luz de la deuda que uno tiene con el ser humano que está en el centro de la investigación, para no hablar de la deuda que uno tiene con cierta noción de verdad, más que de verosimilitud. La prueba de si hemos cumplido con el criterio de verdad no debería ser que la persona biografiada se reconozca a sí misma en el retrato, sino que nuestra representación de segundo orden esté completa y sea plausible. De hecho, las obras sugerentes de Erik H. Erikson $(1975 ; 1993)$ y su idea sobre la intersección de la historia de vida y "el momento histórico"

Véase mi ensayo sobre el testamento de Alamán, Van Young (2014: 101-109). 
me han guiado al tipo de biografía que espero hacer de Lucas Alamán, aunque me aleje del tipo de estudio que hizo el propio Erikson, una biografía que se ha psicologizado y que no es propiamente psicohistórica. Esto sugiere la aplicación de ideas de sentido común sobre la psicología que rozan la fina línea entre un enfoque psicoanalítico no doctrinario y el uso de conceptos más comunes, disponibles en el mundo posfreudiano.

"Procedo de una de las familias más antiguas y distinguidas de Guanajuato". ${ }^{3}$ Así escribía Lucas Alamán el relato de sus orígenes y su infancia a finales de la primavera o durante el verano de 1833. En la siguiente década regresó al texto, aunque no es claro cuántas veces y en qué circunstancias. En el transcurso de estas revisiones, se fue distanciando cada vez más de las experiencias de su juventud y se orientó hacia la obra de cinco tomos sobre la Independencia mexicana, Historia de Méjico, que hoy conocemos. Alamán comenzó a redactar las memorias de su vida y durante el periodo en el que permaneció escondido en la ciudad de México para evadir las audiencias ante un gran jurado de la Cámara de Diputados por las acusaciones en su contra, de presunta complicidad en el asesinato del presidente Vicente Guerrero en febrero de 1831. El estadista, un hombre que frisaba los 40 desde principios de la década, quedó casi relegado a un autoexilio por más de un año. Los pensamientos de los exiliados suelen volcarse no sólo hacia el hogar, sino hacia el pasado. Es comprensible, pues el hogar está en el pasado y también se lleva dentro del exilio en el presente. En una suerte de prolegómeno a su relato sobre sus orígenes y el Guanajuato de su infancia y primera juventud, Alamán refiere que no tenía el propósito de publicarlo, sino que lo escribió para su propio entretenimiento: "Escribo pues para divertirme. Si alguno más tarde se divirtiese con mis escritos... téngalo por bien y buen provecho”. Sus memorias, entonces, tenían el evidente designio de ser una especie de mensaje en una botella, arrojado al mar de las casualidades. Es difícil saber si el autor era insincero, pero me inclino a pensar que él era su propia audiencia. Lo cierto es que nada de estos orígenes personales apareció en sus obras posteriores, salvo por algunas huellas en el panfleto condensado y más bien allanado desde el punto de vista emocional que publicó en 1843. Para describir las circunstancias en que escribió las memorias, Alamán invoca el Decamerón, de Giovanni Bocaccio, y la peste de Florencia en la que se ubican los cuentos. Advierte que durante su propio exilio interno una epidemia de cólera asolaba a la ciudad de México justo más allá de las paredes de su santuario. Aunque lleva el título de "memorias", la obra del estadista cruza la frontera necesariamente porosa con la autobiografía, lo que justifica el tratamiento que le doy como tal, además de que las circunstancias de su escritura le dan una agudeza adicional.

La década en la que se escribió el documento fue culminante en la vida del autor. En ella subió hasta el pináculo de su poder político, como ministro principal en el gobierno derrotado de Bustamante, la "administración alamánica”. Luego comenzó el descenso hacia el otro lado y vio destrozadas sus esperanzas de hacer una gran fortuna personal con sus esfuerzos fallidos de resucitar la industria minera con base en inversiones inglesas, y la bancarrota en 1843 de la fábrica textilera Cocolapan, en Orizaba.

\footnotetext{
"Memorias de don Lucas Alamán" es el título moderno de la obra. Una segunda portadilla, seguramente escrita por el autor, lleva el título “Memorias de D. Lucas Alamán, Ministro de Relaciones exteriores e interiores de la República Mexicana en diversas épocas. En las que se contiene la verdadera historia de esta República desde el año de 1808 en que comenzaron las inquietudes que condujeron a su independencia hasta el año de 1843. Escritas por él mismo" (СEHM). Hasta donde sé, este largo fragmento autobiográfico no ha sido publicado. Alamán escribió después un esbozo autobiográfico muy condensado de sus primeros 50 años, publicado como "Autobiografía de D. Lucas Alamán" (Alamán, 1947: 11-28). Véase también Valadés (1977).
} 
En más o menos esos mismos diez años, México siguió precipitándose en la inestabilidad política —la situación económica es más ambigua-, con cambios vertiginosos en la dirigencia y las estructuras de gobierno nacionales, la consolidación del pronunciamiento como uno de los mecanismos más usuales entre los ambiciosos generales políticos para hacerse del poder central, un gran embrollo internacional con Francia, la pérdida definitiva de Texas, etc. El fragmento autobiográfico de 1833-1834 no ofrece una narración completa de su vida, sólo de su niñez y juventud hasta la adolescencia. Si fuera verdad que los histéricos sufren de reminiscencias, afirmación de Freud que cobró tanta fama, con mucha más razón las han de padecer los autores de memorias y autobiografías, pues ven el presente plagado de riesgos y el futuro igualmente incierto. A fin de cuentas, los historiadores también viven en el permanente abrazo de la nostalgia, una de tono y densidad diferentes. En un hombre con una sensibilidad histórica tan aguda y fértil como la de Alamán, puede entenderse esa tendencia natural a buscar refugio en el pasado e idealizarlo en el proceso, no sólo en el plano personal, sino también en uno más amplio y social. Henos aquí, ante un hombre de mediana edad que rememora las escenas de su juventud y su historia familiar, y de paso crea en retrospectiva una especie de "romance familiar". Es importante recordar que cuando comenzó a escribir éstos, sus fragmentos autobiográficos inconclusos, Alamán estaba exiliado del mundo público en el que había figurado de modo tan conspicuo durante más de una década, separado de su familia y sus amigos, lejos de las actividades de su rutina diaria. Sus asuntos económicos — el manejo de su hacienda en Celaya, sus inversiones, etc.- - en el mejor de los casos, estaban paralizados y lo más probable es que estuvieran en caída libre.

También podemos vislumbrar en este relato autobiográfico los primeros destellos de los escritos históricos posteriores de Alamán y de sus actitudes

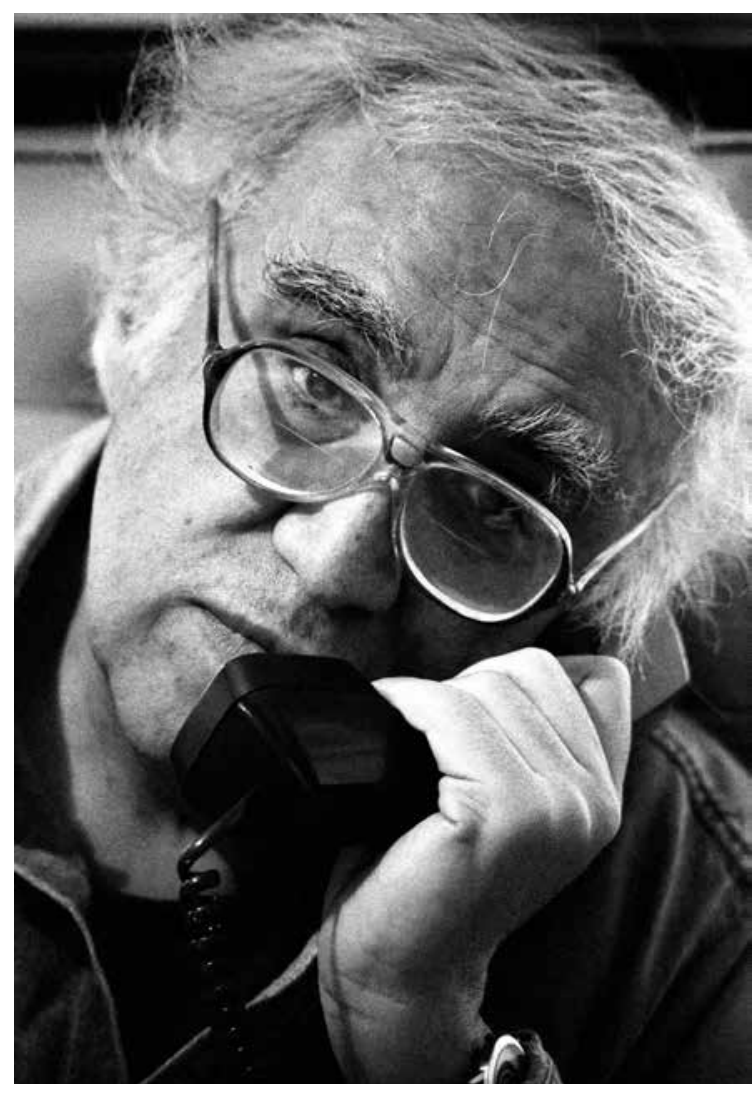

Ricardo Ramírez Arriola/ARchivo360.com • Carlos Monsiváis, escritor, periodista y cronista, durante una entrevista realizada en su casa, de la colonia Portales. Ciudad de México, 1999.

ante la transición del país de colonia a nación. Aquí se pone en evidencia lo que llegó a ser uno de los pilares de su conservadurismo ideológico y de una posición sumamente crítica, incluso condenatoria, ante el proceso de la Independencia mexicana: su evaluación positiva — aunque no falta de maticesdel régimen colonial español, formulada en términos individualizados que enlazan la historia personal con la historia pública. En cuanto a la distinción entre la composición de unas memorias enfocadas sobre todo en la evocación de sus tiempos y una autobiografía más íntima, introspectiva, para la que en cualquier caso había pocos precedentes en el mundo de habla hispana, los propósitos de Alamán fueron 
claros, aunque en la ejecución la distinción se borra. De manera explícita escribe que intenta relatar aspectos de su historia personal y familiar para ilustrar temas mayores, y no tanto por el interés inherente que pudieran tener para un lector. No obstante, hay un tono elegiaco claro en la descripción del Guanajuato de su niñez y juventud, al que evidentemente pretendía dedicar mucha más atención mediante las "anécdotas privadas" que menciona y que nunca llegó a contar. En la medida en que los primeros pasajes de las "Memorias" combinan lo personal y lo político, vale la pena analizarlos con detalle y citarlos completos, pero como no dispongo del espacio para hacerlo, los sintetizo. ${ }^{4}$

Un epígrafe de las Tristezas, de Ovidio, que evoca su propio y melancólico aislamiento, y la esperanza de que la composición de sus memorias le traerá solaz y distracción sirven a Alamán para acometer una discusión sobre la escritura de las memorias y de la historia en general. Si bien este pasaje puede parecer ortogonal respecto de mi tema central —el arco de vida de Lucas Alamán reflejado en las memorias de su juventud y sus escritos tardíos-, de hecho es integral en el tratamiento que le doy. Alamán afirma de manera categórica lo que sugerí líneas atrás: "Las memorias históricas que forman un ramo tan importante de la literatura francesa, casi no han ocupado hasta ahora a los escritores en nuestra lengua castellana". Señala que el género de las memorias revela que:

Frecuentemente los mayores acontecimientos dependen de causas pequeñas y aun ridículas que la gravedad de la historia se ofendería de presentar en todos sus pormenores, $\mathrm{y}$ estos pormenores son no obstante los que hacen conocer a los hombres... $[\mathrm{H}]$ ay todavía en casi todas las grandes acciones circunstancias menudas, y acaso poco favorables al personaje que en ellas figura, que el historiador y el trágico se esfuerzan en cubrir con la majestad del ropaje con que visten a sus héroes, mientras que el memorialista y el poeta cómico se empeñan en presentarlos al natural y aun a veces con alguna malignidad. ${ }^{5}$

Este Alamán es muy diferente del autor de la Historia de Méjico, como ya tendré ocasión de señalar en unos momentos: diferente en el tono, en su filosofía de la escritura de la historia y en sus visiones de la historia misma. En estas memorias truncadas da cabida a elementos burlescos en el desarrollo de la historia, a la contingencia y a un amplio margen de indeterminación en los grandes sucesos.

El elemento más interesante de la Piedra Rosetta que son las memorias de Lucas Alamán es, en mi opinión, su construcción de lo que he llamado "la caída": la pérdida progresiva, intergeneracional, de fortuna y posición social de su familia. Su propósito, escribe, no es recordar su propia juventud y sus orígenes familiares, sino pintar un cuadro de la forma en que las familias de la elite vivían a finales del siglo XVIII. Sin embargo, si logra pintar este cuadro, es gracias a sus recuerdos. Para no dilatarnos en la cuestión de la genealogía familiar, sólo señalaré que la fortuna de la dinastía materna se labró en la plata y el fundador fue el tatarabuelo de su madre, Francisco Matías de Busto, un criollo acogido en la nobleza a principios del siglo XVIII bajo el título de marqués de San Clemente. Su gran riqueza fue extraída principalmente de la mina Mellado en Guanajuato, parte de la veta de otras minas más conocidas, como La Valenciana y la de Rayas, y también relacionada con la mina de Cata, de la que le pertenecieron algunas acciones y aún hoy se explota, aunque el propio Alamán la declarara carente de valor durante su vida. Esa pérdida de predominio

\footnotetext{
4 El texto entero se discute con detalle en el capítulo 2 de Van Young (inédito).

$5 \quad$ CEHM, Memorias de Lucas Alamán 1808-1843, fondo DCLXXIV, carpeta 53.
} 
económico y social que parece haber atormentado a Alamán en su vida personal, se preveía en la transmisión de la riqueza minera desde la primera generación del marqués a sus hijos, a su dispersión a lo largo del tiempo debido a segundos matrimonios y al exceso de vigor reproductivo. Escribe Alamán que la numerosa progenie de los dos primeros nobles entre los Busto produjeron:

Una escena de despilfarro y desorden que condujo a la ruina y miseria a una de las más opulentas familias que ha habido en este país y que verificó en ella literalmente aquel proverbio que tan al vivo expresa la rápida destrucción de las familias en este país: el padre mercader, el hijo caballero y el nieto pordiosero. ${ }^{6}$

De la familia Busto y sus ramas cita en particular un proverbio que en sus tiempos seguía usándose en Guanajuato: "Bustos, burros y bastones, en Guanajuato a montones”. En mi opinión, Alamán se entrega a una casi obsesiva profundidad de detalles para trazar la genealogía familiar de su madre y se remonta varias generaciones atrás. Explica que si se extiende el ejemplo de esta saga familiar a una historia más general, el lector puede darse una idea de la formación de "aquella especie de aristocracia que ha existido en este país” y de la industria minera de Guanajuato "ahora [en los años de 1830] en el punto de extinción". 7

El viaje de Alamán por la añoranza y melancolía de la aristocracia minera tiene desde luego interés por sí mismo, aunque lo más importante es que erige el escenario real e imaginado de su niñez y los primeros años de su vida adulta, así como el de las memorias del hombre maduro que mira hacia su pasado. Su ardiente deseo de preservar el reconocimiento social y sus esfuerzos por recuperarlo ante una narrativa de nostálgica decadencia en la historia familiar explican mucho de su vida. Me parece que en el contexto de estos orígenes exaltados, las circunstancias de su vida de niño y hombre joven son como una larga sombra que se proyecta sobre la madurez no sólo del estadista, sino también del pensador, del crítico de la sociedad mexicana y aun del empresario privado. Como figura relevante en los gobiernos de 1823 a 1825 , de 1830 a 1832, y de 1853, fue en gran medida responsable de una serie de políticas que, independientemente del acierto con el que hayan logrado enfrentar los problemas del mundo real, también hablan de sus preocupaciones privadas. En el ámbito público, su relato de una "edad de oro perdida" dio forma, creo, a sus opiniones y su procedimiento político sobre la forma en que aquella debilitada aristocracia de títulos de su juventud podría reconstituirse como una aristocracia natural cuyos talentosos miembros guiarían el destino de la joven entidad política desde las elevadas cimas de una nación política estrictamente delimitada, en la que dominarían los hombres cultivados, decididos e impecablemente íntegros, los "hombres de bien" a quienes los historiadores modernos describen como una clase política importante en tiempos de Alamán (Costeloe, 1993). Cualesquiera que fueran sus temores práctica y filosóficamente fundados ante, por ejemplo, los procesos electorales democráticos, y así fuera mucho o poco lo que estas opiniones coincidieran con el pensamiento de los conservadores en el mundo atlántico, su historia personal explica en gran medida su férrea oposición a las prácticas de elección popular directa.

Por otra parte, los sentimientos de pérdida de posición surgidos en su juventud bien pueden haberlo motivado, para compensar, a ir más allá de sus posibilidades como empresario privado. De hecho, el fragmento autobiográfico termina cuando admite avergonzado haber vendido con gran beneficio,

$6 \quad$ Ibidem

7 Ibidem. 


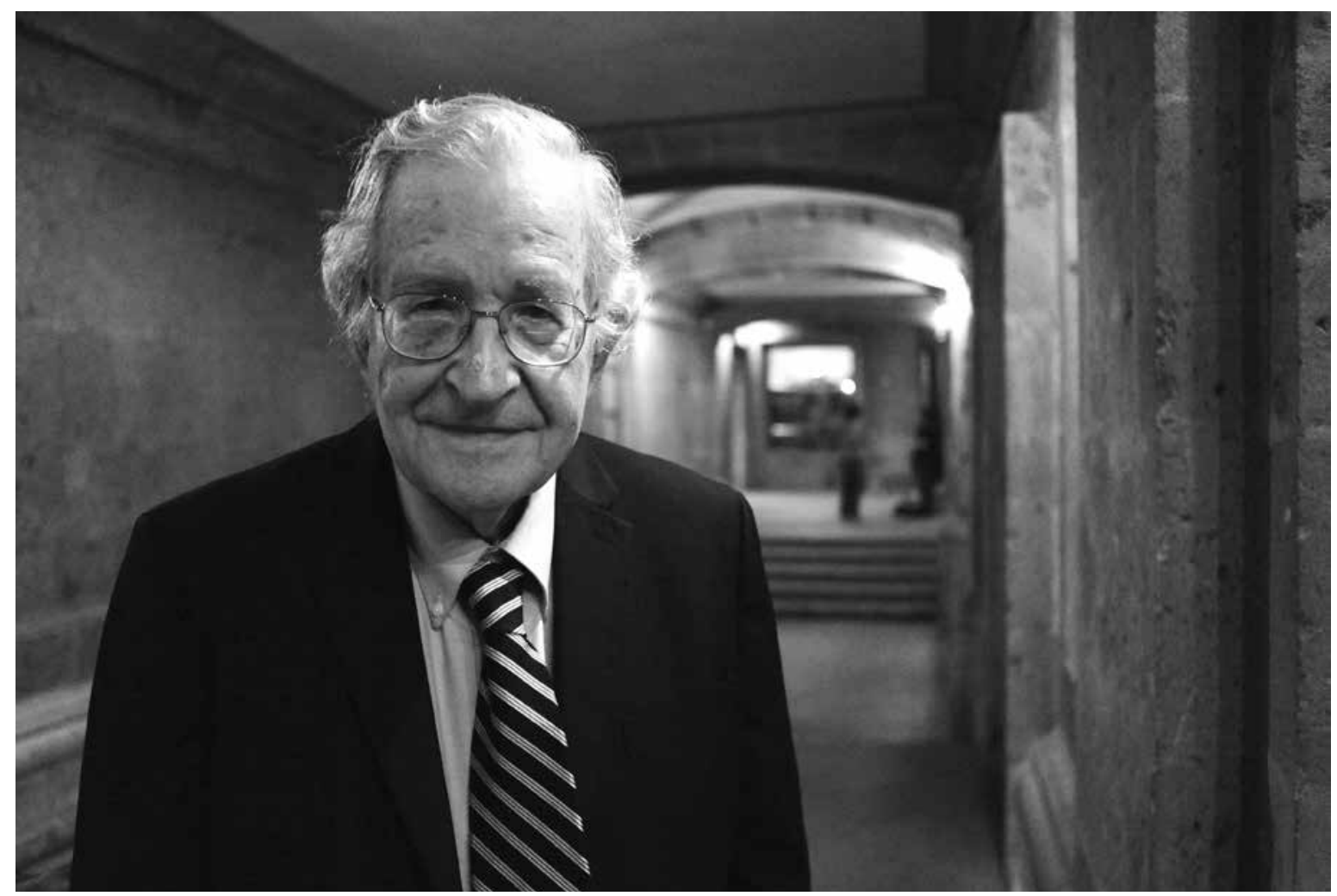

Ricardo Ramirez Arriola/ARChivo360.com • Noam Chomsky, lingüista estadounidense, minutos después de recibir el doctorado honoris causa de la Universidad Nacional Autónoma de México. Palacio de Minería, ciudad de México, 23 de septiembre de 2010.

en 1824, la casa en la que nació y creció, que aún se conserva en el centro de Guanajuato, transformada en un hotel-boutique, La Casona de Don Lucas. Es probable que destinara el capital logrado con la transacción a sus inversiones mineras durante la década de 1820 o a la compra de haciendas en la región de Celaya. La iniciativa política de Alamán, cuando fue el principal ministro del gobierno de 1823 a 1825, para reducir las restricciones legales a la industria minera puede interpretarse a la luz de su historia familiar. La medida no sólo tenía por objetivo servir a los intereses de un México que necesitaba capitales con urgencia y a los de una industria minera devastada, sino también restaurarle a él en particular - $-\mathrm{y}$ en la misma forma- la fortuna que sus ancestros vieron esfumarse a lo largo de varias generaciones.
Sus inversiones en la minería y en las haciendas no le trajeron la riqueza pretendida, tampoco vio coronados por el éxito otros esfuerzos por recuperar parte del lustre de la fortuna familiar originaria. El peor de estos episodios fue su participación como socio administrador de una enorme fábrica de hilados de algodón cercana a Orizaba a finales de la década de 1830 y principios de la de 1840. La empresa fracasó y quebró en pocos años. En este caso, la vinculación con la política pública y la modernización de la economía política fue el establecimiento en 1830, bajo su dirección, del famoso Banco de Avío. El desastre lo dejó envuelto en una maraña de juicios y deudas de la que no pudo desenredarse durante sus últimos diez años de vida. Al parecer, se vio obligado a liquidar gran cantidad de propiedades, de tal suerte que llegó 
al final de su vida, en 1853, mucho más pobre de lo que había sido 15 años antes.

El otro extremo del puente que ahora tiendo entre la historia familiar y los años de juventud de Alamán —aunque refractados por la memoria de un hombre de mediana edad que vivía un exilio político- se ancla en su magistral Historia de Méjico, publicada en cinco volúmenes entre 1849 y 1852. Puede considerarse una de las mayores obras de la historiografía mexicana del siglo XIX, ciertamente la mayor de todos los historiadores mexicanos sobre la lucha por la independencia y todavía hoy referencia obligada tanto por su material valioso y abundante como por su agudeza interpretativa. ${ }^{8} \mathrm{Su}$ Historia fue el resultado de un considerable distanciamiento de la vida pública, un retiro que no fue en modo alguno absoluto y obviamente reversible, pero que sin embargo fue un retiro. Sus problemas de salud recurrentes tuvieron algo que ver, así como la muerte de algunos de sus hijos, pero estas experiencias eran relativamente comunes en esa época. Tal vez también pensara ganar algo de dinero con las ventas de la obra para dejar a su viuda y sus hijos menores en una posición económica más segura, como lo haría con sus memorias unos años después, ya moribundo, el ex presidente estadounidense y héroe de la Guerra Civil Ulysses S. Grant.

Pero había otros motivos. Alamán comenzaba a peinar canas cuando el país mismo, con la guerra del 47, estuvo a un paso de convertirse en un Estado fallido o incluso atravesó ese umbral, según la manera en que uno quiera definirlo. Mucho han escrito los historiadores sobre el trauma nacional de la guerra y el doloroso balance hecho por políticos e intelectuales mexicanos de las condiciones en que el conflicto armado dejó al país. Mientras Alamán escribía los últimos volúmenes de la Historia, se vivían las consecuencias de las revoluciones de 1848 en Europa, sobre las que él tenía muchas fuentes. En términos de su propia trayectoria en la vida pública, cuando aún estaba por venir su brevísimo retorno al poder como arquitecto de la última administración del sempiterno presidente Antonio López de Santa Anna, Alamán ha de haber sentido que araba en el desierto, como describió Simón Bolívar su propia carrera política. Después de producir varios volúmenes de narraciones históricas sobre el periodo colonial, en esos años Alamán se dispuso a contar la historia del movimiento de independencia de su país. El propósito central de la obra era retratar los diez años de insurgencia contra España como un momento histórico en el que se plantaron las semillas del desastre que sobrevendría y en el que se consumó la pérdida del potencial de la Nueva España cuando tropezó con su vida como Estado-nación independiente. Si bien su famoso contemporáneo y adversario político, el abogado, sacerdote e historiador liberal José María Luis Mora pensaba que la violencia de tintes étnicos de los años de 1810-1811, en la fase inicial de la lucha encabezada por el padre Miguel Hidalgo y Costilla, había sido un mal necesario, Alamán la veía como un mal a secas. Así que en un sentido real, el arco de la trayectoria de Alamán siguió el desplazamiento de su propio país hacia una etapa que rayaba en la disolución. La Historia de Méjico fue la destilación de una vida de febril actividad en los asuntos públicos, el fruto no sólo de su madurez, sino también de la desilusión. En las últimas páginas de esta obra escribió su famosa observación de que México había llegado de la infancia a la decrepitud sin haber pasado nunca por la madurez.

Quisiera ocuparme ahora del Alamán historiador. Hay cierta paradoja en que Alamán sea conocido hoy sobre todo como historiador, pues aunque adquirió muy pronto en la vida la sensibilidad histórica, el oficio de historiar lo desarrolló tarde y sólo para usarlo ante todo como un arma en la lucha política. Como historiador no fue

8

Sobre la historiografía de la Independencia de México, en español y en inglés, véase Van Young (2012). 
ningún romántico, sino un realista que encajaba mejor del lado de la historiografía decimonónica de Von Ranke que del lado heroico-romántico, y en su obra se esforzó por lograr la objetividad. No obstante, es difícil dejar de percibir cómo se filtran sus temores y su lectura de la política. Es casi imposible no ver en su descripción de la caída de la Alhóndiga de Granaditas de su natal Guanajuato a fines de 1810 la influencia de los relatos de la caída de la Bastilla, uno de los episodios inaugurales de la Revolución francesa que él aborrecía tanto. Por otra parte, la escritura de la historia, en este periodo - practicada por cronistas tan famosos como Alamán, Carlos María de Bustamante, Lorenzo de Zavala, el padre Mora y otros-, fue parte de una batalla política entre liberales y conservadores sobre quién habría de controlar el futuro del país al interpretar el pasado de una u otra forma.

Dadas las fuentes políticas de la escritura histórica de Alamán, no sorprende que su gran Historia de Méjico haya comenzado a principios de 1830 como una memoria personal que contaba mucho, pero no todo, porque se proponía ser un relato de su vida en la política, aunque se concentró en sus orígenes familiares y su juventud sin llegar nunca a la vida pública. Los títulos de estas dos obras se asemejan, pero tienen un tono diferente. La primera, que he llamado "Memorias", fue escrita alrededor de 1833, aunque está fechada una década después. Lleva por título "Memorias de D. Lucas Alamán, Ministro de Relaciones exteriores e interiores de la República Mexicana en diversas épocas. En las que se contiene la verdadera historia de esta República desde el año de 1808 en que comenzaron las inquietudes que condujeron a su independencia hasta el año de 1843. Escritas por él mismo", mientras que la obra magistral de finales de la década de 1840 y los primeros años de 1850 se llama "Historia de Méjico desde los primeros movimientos que prepararon su independencia en el año de 1808 hasta la época presente".
Luego de haber dejado de lado sus memorias durante varios años, las retomó al parecer en 1843, más o menos una década después de haberlas comenzado y unos cinco años antes de empezar a escribir su magnum opus. Recordemos que todavía estamos viendo un texto inédito en manos del propio autor y estos últimos párrafos son una especie de punto intermedio en el puente que atravesamos con él. Para ese momento, Alamán ya había asumido una voz mucho más distanciada, filosófica. Escribía sombríamente, en un registro fatalista, dejaba menos lugar al azar en la historia y abandonaba al menos en parte el tono burlesco presente en la sección introductoria. Casi podemos oír la gran rueda de la fortuna girando al fondo de la escena, los estratos de detritos históricos que se sedimentan unos sobre otros a lo largo de milenios, y aunque todavía escribe sobre las "circunstancias", moja la pluma en hiel. Me parece que es indispensable citar el pasaje completo:

Si los grandes acontecimientos políticos que mudan el aspecto del globo hubiesen de dirigirse por sólo la voluntad, la conveniencia o el amor propio ofendido de los soberanos interesados en la permanencia del estado de cosas que creen fundado en los derechos que han adquirido, nunca se habrían verificado las grandes revoluciones que han levantado de la nada a aquellas naciones que han venido a ser señores de una gran parte del mundo, y que han dado origen después con su destrucción a otras naciones, que en el orden impenetrable de la providencia han hecho papel a su vez, sufriendo iguales vicisitudes. Pero hay una fuerza de las circunstancias, hay tales combinaciones de estas que hacen fuerza a la voluntad, inducen nuevas conveniencias e imponen al amor propio la necesidad de ceder...

Sin mostrar otros ejemplos de estas verdades, que la historia general demuestra a cada página, encontramos uno muy notable en la nación de que 
hicimos parte y a cuya destrucción debemos nuestra existencia política. Procediendo ella misma de la desmembración del imperio romano, dividida en mil porciones independientes con la invasión sarracena y sus consecuencias, y reunida de nuevo bajo un solo cetro, extendió su poder inmensamente en todo el globo conocido, para dividirse otra vez en una multitud de naciones a quienes hizo con tenacidad la guerra para impedir su independencia, la que ha acabado por reconocer más tarde, perdiendo todo el fruto que hubiera podido sacar sometiéndose antes al imperio de las circunstancias, y así es como la figura de este mundo va mudando sin cesar, sucediéndose unos a otros los

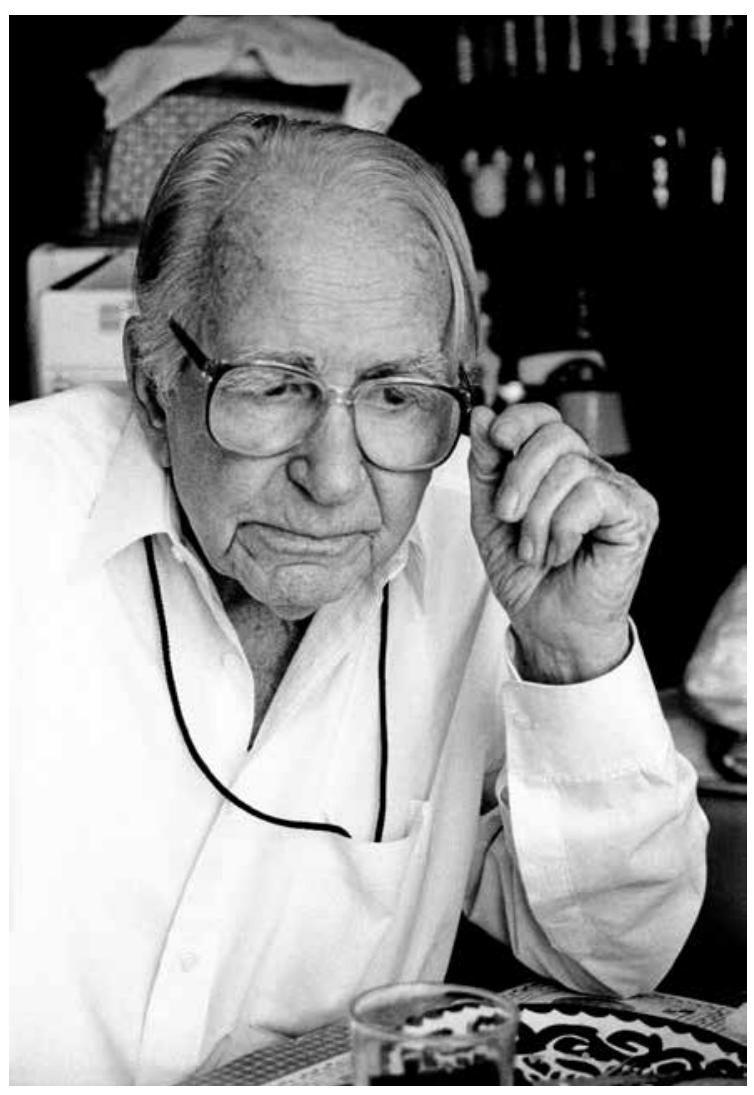

RICARDO RAMIREZ ARRIOLA/ARCHIVO360.COM • Walter Reuter, fotógrafo germano-mexicano, luchador social contra el nazismo y el fascismo en Alemania y España. Ciudad de México, 1999. imperios y las naciones, sin que haya poder humano bastante a impedirlo. ${ }^{9}$

Algunos años después, cuando se sentó a escribir la introducción de su gran historia, Lucas Alamán cuestionaba que México hubiera existido como nación durante la época anterior a la Conquista o durante la Colonia, según insistían algunos de sus contemporáneos, y mucho menos después de su independencia de España y de la formación de un Estado nacional. La implicación era que México serviría como un ejemplo exhortatorio para otros Estados hispanoamericanos sucesores en cuanto a la improcedencia de las instituciones republicanas y el fracaso en el intento de inculcar un espíritu de "mexicanidad" entre la población, única base firme para una existencia política ordenada. Si bien reconoce en su prosa imperturbable y laberíntica que la independencia de México era inevitable, no deja de exaltar el periodo de la Colonia española como una época de buen gobierno, prosperidad y orden social, y de lamentar la violencia civil y militar irrestricta desencadenada por la rebelión del padre Miguel Hidalgo, y el estado de la nueva nación después de sus primeros 25 años de vida. Con la ventaja de la retrospectiva y de su propio papel central en la política mexicana a lo largo de tres décadas, Alamán se ocupa en una cuestión vital para la mayoría de los escritores del periodo: por qué el México que acaba de obtener su independencia ha gozado de tan poco éxito político o económico, y en particular, por qué el país se ha convertido tan fácilmente en víctima de la poderosa república hermana del norte. A modo de respuesta, construye una narrativa histórica del fracaso que comenzó con el rechazo de la herencia española de parte de los desencaminados jefes insurgentes, que condujo a una guerra de clases. Según

CEHM, Memorias de Lucas Alamán 1808-1843, fondo DCLXXIV, carpeta 53. 
su razonamiento, de este error fundamental surge la anarquía y la debilidad del periodo republicano inicial, la experimentación política con ideas extranjeras radicales que no se avenían con la realidad mexicana — aquí la influencia de Edmund Burke en su pensamiento es fuerte y explícita- y la intromisión en la religión tradicional por las fuerzas de la Ilustración que produjo la debacle de 1847. En otras palabras, para Alamán no hubo demasiada España en México, sino demasiado poca.

Quisiera avanzar hacia la conclusión con una cita del final de su obra; es larga, lo reconozco, y en mi opinión, muy reveladora. En ésta, su oscura visión de la historia nacional, desplegada a lo largo de su vida y de muchas formas paralela a ella, se materializó en todo su esplendor burkeano y por ella es conocido hoy:

Al ver en tan pocos años esta pérdida inmensa de territorio; esta ruina de la hacienda, dejando tras de sí una deuda gravosísima; este aniquilamiento de un ejército florido y valiente, sin que hayan quedado medios de defensa; y sobre todo, esta completa extinción del espíritu público, que ha hecho desaparecer toda idea de carácter nacional: no hallando en Méjico mejicanos, y contemplando a una nación que ha llegado de la infancia a la decrepitud, sin haber disfrutado más que un vislumbre de la lozanía de la edad juvenil ni dado otras señales de vida que violentas convulsiones, parece que habría razón para reconocer con el gran Bolívar, que la independencia se ha comprado a costa de todos los bienes que la América española disfrutaba, y para dar a la Historia de aquella el mismo título que el venerable Obispo Casas [sic] dio a su Historia general de Indias: "Historia de la destrucción de las Indias". Pues lo que ha pasado en Méjico, se ha repetido con muy ligeras y temporales excepciones en todo lo que fueron posesiones españolas, sintiéndose en Méjico los efectos del desorden de una manera más dolorosa, por tener un vecino poderoso que ha contribuido a causarlos y ha sabido aprovecharse de ellos.

Estos funestos resultados han dado motivo para discutir, si la independencia ha sido un bien o un mal y si debió o no promoverse. La cuestión es ociosa después de consumado el hecho, tanto más, que nunca estos grandes sucesos son en las naciones resultado de cálculos de prudencia, sino efecto de casualidades o combinaciones que están fuera de la previsión humana, y el curso de las cosas ha sido tal, que si Méjico no hubiera hecho su independencia en 1821, la habría hecho poco después...

La independencia, pues, no sólo era posible, pero ni aun prematura hubiera parecido, si no lo hubieran sido mucho las novedades que con ella han querido introducirse, dado caso que ellas sean posibles en ningún periodo de la existencia de las naciones, que no se han formado con el género de instituciones que se ha pretendido establecer. En esto ha consistido todo el mal... (Alamán, 1969, 5: 566-567).

Así iba el Alamán entrado en años, cada vez más desilusionado, lejos de cualquier tipo de revelación personal, de las memorias, de una discusión sin final definido sobre el destino del país, encauzado hacia una visión mucho más distanciada, olímpica, impersonal y oscura. Su ambivalencia ante las instituciones de gobierno justas para México y sobre las posibilidades económicas del país se había congelado en el desengaño. Sus esperanzas de recuperar la posición social y la riqueza de su familia se habían marchitado.

Para concluir, quisiera retomar el tropo de la Piedra Rosetta en lo relativo a Lucas Alamán, en particular la plausibilidad de invocar sus memorias truncadas para desencriptar no sólo la posterior y mucho más voluminosa y formal Historia de Méjico, sino, más allá, la trayectoria de su vida entera. Si se deja fuera el peligro de una simplificación excesiva, ¿cómo justificar que se tome por Leitmotiv de su vida 
esta especie de obsesión con la pérdida de estatus tal como resalta en las memorias de la década de 1830? Me parece que se pueden ofrecer varias premisas para validar este movimiento interpretativo, pero aquí hago hincapié sólo en dos de ellas. En primer lugar, hay un grado razonable de "correspondencia” entre lo que sabemos de los actos y palabras de Alamán y el modelo que he construido de sus disposiciones conformadas en parte por su niñez y su primera juventud, por sus recuerdos de esa vida y su visión de esa memoria proyectada en la pantalla de su experiencia como un hombre adulto. En otras palabras, ¿es plausible mi interpretación de las fuerzas que lo movían? Creo que tres de las principales esferas de su vida demuestran que lo es: sus ideas políticas, sus actividades como empresario y su trabajo como historiador. En segundo lugar, una de las principales herramientas legítimas del biógrafo es la intuición de la vida interna, de los procesos de pensamiento y del estilo personal de su sujeto, intuición obtenida gracias a una larga e intensa lectura y relectura de los documentos.

Lucas Alamán fue un conservador no tanto por lo que temía perder sino por lo que había perdido. En parte fue un modernizador por lo que esperaba recuperar. En otras palabras: Alamán fue un nostálgico más que un reaccionario. Si la combinación de sus orígenes personales, sus primeras experiencias y las circunstancias específicas de los comienzos de la república en México hubieran sido diferentes, su persona histórica lo hubiera sido también. Esta trayectoria personal, una historia de lo plausible para un individuo determinado en un entorno histórico determinado, es a lo que Erikson se refiere como la intersección de una historia de vida con un momento histórico. Así como cualquier otro de los registros que elaboró, Alamán nos deja ver a través

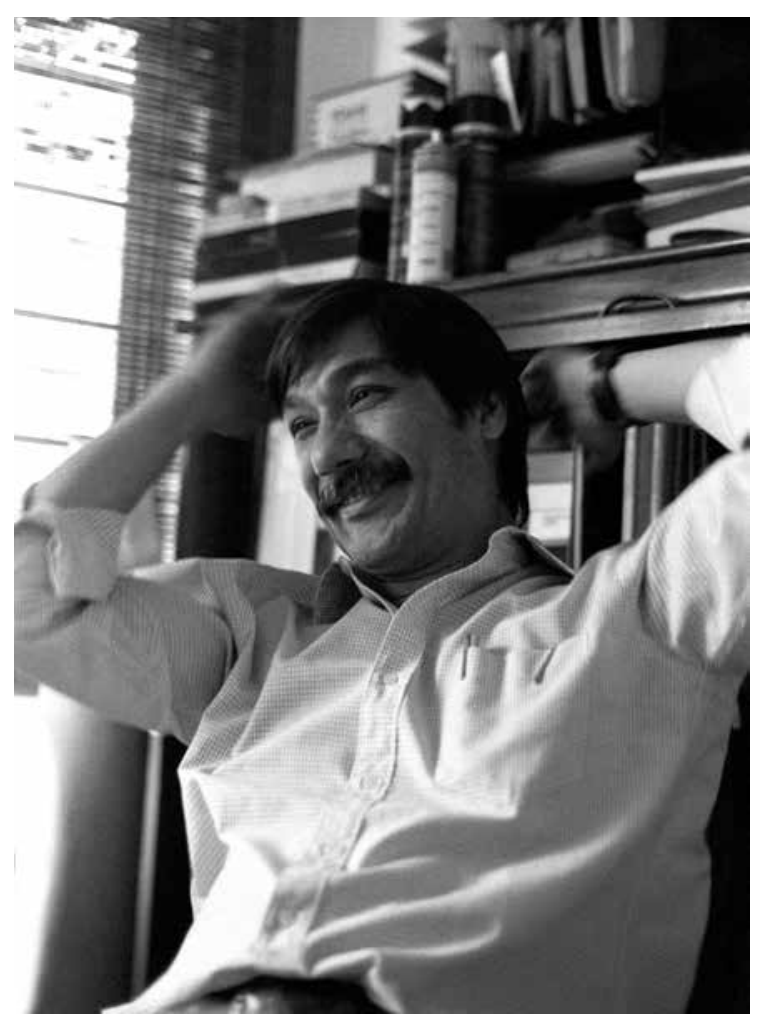

Ricardo Ramírez Arriola/ArChivo360.com • Gilberto Chen Charpentier, fotógrafo e impresor fotográfico, en el laboratorio LaserFoto. Ciudad de México, 1999.

de sus propios ojos sus memorias su vida y la época en que vivió, formuladas quizá para adecuarse a un proyecto de autofiguración y cubiertas por el velo de la nostalgia, uno tejido por su afilada inteligencia. Su persona y sus acciones de la edad adulta estuvieron sobredeterminadas, conformadas no sólo por sus orígenes y su juventud, sino también por las circunstancias de su tiempo: la inestabilidad política, el fermento de las ideas, las tergiversaciones de la construcción del Estado y la nación, y su fortuna personal. D 


\section{Bibliografía}

Alamán, Lucas, 1947 [1843], “Autobiografía de D. Lucas Alamán”, en Lucas Alamán, Obras, Rafael Aguayo Spencer (ed.), t. 12, Jus, México, pp. 11-28. , 1969, Historia de Méjico, 5 vols., México, Jus.

Burke, Edmund, Reflections on the Revolution in France, 2001 [1790], Stanford University Press, Stanford.

Calderón de la Barca, Fanny, 1970, Life in Mexico: The Letters of Fanny Calderón de la Barca, Howard T. Fisher y Marion Hall Fisher (eds.), Anchor Books/Doubleday, Garden City.

Costeloe, Michael P., 1993, The Central Republic in Mexico, 1835-1846: Hombres de Bien in the Age of Santa Anna, Cambridge University Press, Cambridge.

Erikson, Erik H., 1975, Life History and the Historical Moment: Diverse Presentations, W. W. Norton, Nueva York. , 1993, Young Man Luther: A Study in Psychoanalysis and History, W. W. Norton, Nueva York.

Prieto, Guillermo, 1906, Memorias de mis tiempos, 2 t., Librería de la Viuda de Ch. Bouret, México y París.

Robinson, Fayette, 1848, Mexico and Her Military Chieftains, from the Revolution of Hidalgo to the Present Time: Comprising Sketches of the Lives of Hidalgo (and Others), Silas Andrus, Hartford.

Valadés, José C., 1977, Alamán: estadista e historiador, Universidad Nacional Autónoma de México, México.

Van Young, Eric, 2012, "No Human Power to Impede the Impenetrable Order of Providence: The Historiography of Mexican Independence", en Eric Van Young, Writing Mexican History, Stanford University Press, Stanford.

, 2014, "El testamento de Lucas Alamán de 1850," en Jorge Alfredo Ruiz (coord.), Un documento, una época. 500 años del notariado en México, Quinta Chilla Editores/Colegio de Notarios del Distrito Federal, México, pp. 101-109.

—_, inédito, "Alamán and Mexico: A Life Together, 1792-1853".

\section{ARCHIVOS}

Centro de Estudios de Historia de México Carso Fundación Carlos Slim (CEHM), Memorias de Lucas Alamán 1808-1843, fondo DCLXXIV, carpeta 53. Benson Latin American Collection (BLAC), University of Texas at Austin. Valentín Gómez Farías Papers, item 1182. José María Luis Mora, París, a Valentín Gómez Farías, ciudad de México, 20 de mayo de 1845. 